NOTICE

This report was prepared as an account of work sponsored by the United States Governnent. Neither the United States nor the United States Department of Energy, nor any of thete employees, nor any of their contractors, gubcontractors, or thelr employees, makes any warranty, expregs or 1mplied, or assumeg any legal liability or cesponsiblitty for the occuracy, completeness or usefulness of any information, apparatus, product or process disclosed, or represents that lt.s use would not infeinge privately omed rlghts.

Printed in the inlted States of America

Avallable from:

Natlousl Technical Information Service

0.5. Department of Comperce 5285 port Royal Road

Springfield, Virginia 22161

Price Printed Cogy $\$ \ldots$, Mierofiche $\$ 4,50$

Pageg

$1-25$

$25-50$

$51-75$

$76-100$

$101-125$

$126-150$

$151-175$

$176-200$

201-225

$226-250$

$251+275$

276-300

301-325

326-350

$351-375$

376-400

$401-425$

426-450

451-475

476-500

500-525

526-550

$551-575$

567-600

NrIS

Selling Price

$\$ 7.00$

$\$ 9.50$

$\$ 10.00$

$\$ 11.50$

$\$ 13.00$

$\$ 14.50$

$\$ 15.00$

$\$ 17.50$

$\$ 19.00$

$\$ 20.50$

$\$ 22.00$

$\$ 23.50$

$\$ 25.00$

$\$ 26.50$

$\$ 28.00$

$\$ 29.50$

$\$ 31.00$

$\$ 32.50$

$\$ 34,00$

$\$ 35.50$

$\$ 37.00$

$\$ 38.50$

$\$ 40.00$

$\$ 41.50$
For documents over 600 pages, add $\$ 1.50$ for each additional 25-page increment. 
S. C. JARDiN, J. DELUCIA, M. OKABAYASHI,

N. POMPHREY, M. REUSCH, S. KAYE, H. TAKAHASHI

Flasma Physics Laboratory, Princeton University

Princeton, New Jersey 08544

\begin{abstract}
The free-boundary, exisymmetrio tokamak simulation code ISC is used to model the transport time scale evolution and positional stability of PBX. A disruptive thermai quench will cause the plasma column to move inward in major radius. It is shown that the plasma can then lose axisymetric stability, causing it to displace exponentially off the ridplane, terminating the discharge. We verify the accuracy of the code by modeling several controlled experimental shots in PBX.
\end{abstract}

\title{
DISCLAIMER
}

This report was prepared as an account of work sponsored by an agency of the United States Governmer1. Neither the United States Government nor any agency the reof, nor any of their cmployees, makes any warranty, express or implied, or assumes any legal hiability or responsibility for the accuracy, compieteness, or useruiness of any information, apparatus, product, or process disclosed, or represents that its use would not infringe privately owne-t rights. Reference herein to any specific comniercial product, process, or service by Irade name. Irademark. manufacturer, or otherwise does tist necessarily constitute or imply its endarsement, recommendation, or favoring by the U/nited Stales Government or any agenty therwol. The views and opinions of authors expressed herein do nol necessarily state or rellect those of the Unirid Sibtes Government or any agetrcy thereof. 
I. INTRODUCTION

The Princeton Beta Experiment $[1,2]$ (PBX) produces a highly noncircular cro:ss-sectional bean-shaped plasma which enables it to sperate at high current and high beta values. A well-known consequence of this cross-sectional shaping is the need to provide both passive and active feedback systems [3] to control the axisymetric instabilities and to maintain the desired crosssectional shape. In PBX, this is accomplished by three sets of passive aluminum plates connected top-bottom in antiseries, and by active feedback control systems governing both the radial field coils (RF) which control the vertical position and the vertical fiesd coils (VF) which control the radial position.

The radial position control and the vertical position control are closely coupled in PBX. This coupling, described further in Sec. $V$, is due to the strong radial variation in both the vertical destabilizing force from the external fields, and in the restoring forees fron the fixed location passive conductors. The combined system is shown to lose stability if the plasma undergoes a sudden loss of thermal energy or a redistribution of current at high beta, high indentation operation.

The Princeton Tokamak Simulation Code (TSC) [4] is used to model this device. This code was developed to model the axisymetric transport time scale evolution and the positional stability and control properties of this [2] and other [5-?] noncircular tokamaks. The code is described in detail and is validated against analytic test problems in Ref. [4]. In this report we first validate the code against experimental data by presenting comparisons with several controlled experimental shots in PBX. We then modei a high beta plasma disruption in PBX and show that a small inward radial shift of the plásme, either caused by sudden thermal loss or by decrease of the plasma

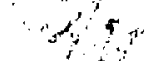


internal inductance, can cause the system to lase ideal MHD time scale stability and the plasma will be lost to an axisymmetric mode. This result is in good agreement with the exoerimental description of disruptive PBX discharges in Ref. $18 \mathrm{]}$.

The modeling analysis presented in this paper is largely numerical, being the output of a large complex computer program, TSC. To be credible, we must show that this program can reproduce known results. Verification only against analytic models, as performed in Ref. [4], still leaves open the possibility that the underlying MHD equations utilized both by the analyiic solution and by the computer program, are an inadequate description of the physinal experiment. To this end, we present comparisons of the code predictions with several controlled experimental shots in Sec. II.

\section{CODE VERIFICATION}

The PBX experiment produces a magnetic data tape each shot on which is written the time history, with millisecond resolution, of the currents in each of the three coil systems; vertical field (VF), shaping field (SF), radial field (RF), the plasma current, and the values of the poloidal magnetic fIux obtained by integrating the loop voltage at eight flux loop locations. We run TSC in a predictive mode, but use the experimentally measured values of the currents in the three coil systems. We also feedback adjust the rate of flux change from the simulation code ohmic heating ( $\mathrm{OH})$ coil system so that the computed total plasma current agrees with the experimentally measured values at each time point.

To test the validity of the simulation model, we then compare computed values of the poloidal flux at the flux loop locations with the measured values. These should agree since the code also simulates the induced eddy 
currents in the adjacent conducting plates and the vacuum vessel. We present the results of several such comparisons.

\section{A. Coils OnIy Shots}

In Figs, 1 through 3 we show the results of three calibration shots in which an individual coil system was activated but no plasma discharge was initiated. In Fig. 1 the VF system was pulsed (with some inductive coupling to the SF) while in Figs. 2 and 3 the SF and RF systems were activated. In part (d) of each figure is shown the flux contours of the magnetic field produced (dotted lines), the location of the experimental flux loops (crosses) the conducting plates, and some of the coils located inside the computational grid. The PBX vacuum vessel and the remaining poloidal flald coils are included in the calculation but are not shown. Their locations may be obtained from Ref. [1]. In these runs, the vacuum vessel was modeled as two vertical rows of zones located at $R=0.7 \mathrm{~m},|\mathrm{z}|<0.8 \mathrm{~m}$ and $\mathrm{R}=2.18 \mathrm{~m}$, $|z|<0.8 \mathrm{~m}$. Each $4 \mathrm{~cm} \times 4 \mathrm{~cm}$ zone has a resistance of $0.012 \mathrm{R}$ ohms.

The passive plates are physically constructed of three up/down pairs of 2.5-cm-thick solid aluminum. Each pair is electrically insulated from the others, but is connected together in midplane reflection antiseries so that if a net positive current appears in one plate segment, then the same net negative current must appear in its reflection. Each of the six plate segments is modeled with eight to ten computational zones as shown, with the constraint applied that the net current in each up/down pair of plate segments sum to zero. This construction makes the field penetration time for the radial field much longer than that for the verticai ireld. Each $4 \mathrm{~cm} \times 4 \mathrm{~cm}$ corputational zone modeling the conducting plates is given an electrical resistance of $r=0.00064 R$ ohms where $R$ is the major radius of that zone in 
meters. The zero net current constmint for plate pairs is imposed as discussed in Ref. [4].

In parts (a) of each rigure are shown the experimentally measured current. traces, which were also used in the calculation. In parts (b) and (c) are shown the comparison between the experimentally measured and the computed values of certain differences of the poloidal flux at the flux loop locations. The agreement between the theoretical and the experimental flux values, as shown in parts (b) and (c) of Figs. 1 thru 3, is seen to be quite good. We see from comparing Figs. $i(b)$ and $3(b)$ that the simulation model is able to reproduce the two time scale response of the passive plates quite well. The radial field in Fig. 3 requires several hundred milliseconds to penetrate, while the vertical field in Eig. 1 penetrates in tens of milliseconds .

\section{B. Vertical Instability}

In this controlled experiment, the plasma was held in a bean-shaped configuration $0.5 \mathrm{~cm}$ above the $z=0$ midplane by adding an offset term to the $R F$ active feedback system. At time $t=0.395$ sec after plasma initiation, the $\mathrm{RF}$ feedback systen is short circuited and the plasma displaces vertically of the midplane with an instability growth time characteristic of the L/R time of the passive aluminum plates.

We model this experiment by running TSC in a predictive mode, but using the values of the actual experimental currents in the VF and SF system as described in the beginning of Sec. II. He include active feedback in the RF system, and offset the computation feedback system to match the offset currenti in the experimental system. The TSC evolves the poloidal and toroldal flelds using a neoclassical resistivity model with a "Z-effective" of 
3.0. The electron and ion temperatures are evolyed in time as described in Fief. [4] using the transport madel described in Appendix A.

The plasma density is not evolved in time. Rather, we assume the density profile is of the form

$$
n(t, t)=n_{0}(t)\left(1-\psi^{B}\right)^{\alpha}+n_{b},
$$

where $\downarrow$ is the normalized poloidal flux which is zero at the magnetic axis and unity at the limiting surface. We adjust $i_{0}(t)$ to agree with the experimentally measured values of the line-averaged dengity. Valies of $a=1.0, B=2.0, n_{b}=4.0 \mathrm{E} 18$ give good agreement with density profile measurements.

We begin the simulation at $t=0.30 \mathrm{sec}$. The plasma evolves into a resistive steady state in which magrietic measurements at the eight flux loop locations agree with the experimental values. At time $t=0.395$ the active feedback system in the code is shut off and the resistivity of uach of the faur computational celis in the feedback coils is set to 0.0003 onms. The magnetic flux surfaces at the time of shutof $\mathrm{f}$ and at $75 \mathrm{~ms}$ after shutoff are shown in Eig. 4. We plat in Fig. 5 the time history ot the difference of the flux in loops 1 and 2 , which is a measure of the vertical dispiacement. The experimental data for this measurement are also plotted in Fig. 5 for comparisan. The agreement is seen to be quite good.

As a sensitivity test, we have performed another simulation with the horizontal conducting plates moved $4 \mathrm{~cm}$ cluser to the plasma both on the top and the bottom. The flux difference plot for this run, also shown in Fig. 5 is substantially different from the origina? simulation and the experimental surves, We can conciude that the simulation program can adecitately resolve this difference between plate locations. 
The TSC uses an "enhanced mass technique" to deal with the severe time scale discrepancy between ideal wave-like and resistive diffusion-like phenomena in a takamak. As described in Ref. [4], this is equivalent to adding a fictitious viscous terin and increasing the ion mass by a large mass enhancement factor, typically several thousand. Normal resistive evolution and resistive time scale instabilities should be independent of this factar, while ideal time scale instabilities should exhibit growth rates proportional to its square root. Thus, as a second sensitivity test, we have rerun this simulation with the mass erhancement factor reduced by a factor of four, and with the artificial viscosity parameter reduced by a factor of two. The curves from these runs coincide with the original curves confirming both that the instability is on a resistive as opposed to an ideal MHD time scale and that the code is adequately converged in these parameters.

\section{POST-DISFUPTIVE PLASMA LOSS}

\section{A. High Beta Stable Evolution}

We have used the TSC to simulate the axisymmetric evolution of a high beta disrharge in PAX. The currerts in the SF and EF coil systems are taken from the experimental data tape for shot \# 95737. The total plasma current $I_{p}$ and the central density $n_{0}$ are adjusted to match the experimental values in the same way as is described in Sec. IIB. In this run the midplane line integral dengity increased nearly inearly from $1.3 \times 10^{19}$ at $t=0.25$ sec to $2.6 \times 10^{19}$ ai $t=0.55 \mathrm{sec}$. We again utillze the anomalous transport model described in Appendix A. A "Z-effective" of 3.0 was used to match that obtained from spectroscopy.

To model the neutral beam injection, we take an ion energy source deposition profile to be a function of the normalized poloidal flux $\tilde{x}$ of the form 


$$
S^{E}(u, t)=S_{0}^{E}(t)\left[\left(\frac{(\tilde{x}-z)^{2}+d^{2}}{d^{2}}\right)(1-\tilde{x})^{2}\right],
$$

where $a=0.1, d=0.5$, and the normalization factor $S_{0}{ }^{E}(t)$ is presoribed to give $1.1 \mathrm{MW}$ infection at $t=0.36 \mathrm{sec}, 2.2 \mathrm{MW}$ at $t=0.41 \mathrm{sec}, 3.4 \mathrm{MW}$ at $t=0.44 \mathrm{sec}$, and $4.5 \mathrm{MW}$ at $t=0.52 \mathrm{sec}$, as shown in $\mathrm{Fig} .8$.

The toroidal currents in the coil systems and in the plasma are shown in Fig. 6 as a function of time. In Fig. $7 a$ we plot the flux differences between the flux loop values $\left(\psi_{3}+\psi_{4}\right)$ and $\left(\psi_{7}+\psi_{3}\right)$ (upper curves), and between $\left(\psi_{3}+\right.$ $\left.\psi_{4}\right)$ and $\left(\psi_{5}+\psi_{6}\right)$ (lower curves). The good agreement between the computed and measured values of the upper curves of flux loop values was aided by allowing the simulation code to adjust a multiplier, $f_{m}$, in front of the anomalous electron thermal transport coefficient as described in Appendix A. The value of $f_{\text {扣 }}$ used in the simulation varied between 0.6 and 1.8 as shown in Fig. 8 . The computed loop voltage, defined as the average of the time derivative of two flux Ioop values, $(1 / 2) d / d t\left(\psi_{3}+\psi_{4}\right)$, is shown in Fig. 7b along with the experimental value.

It is remarkable how well both $: 2$ the computed flux-loop differences of Fig. 7 agree with their respective experimental values. Even with the upper curve agreement being facllitated by adjusting the multiplier $f_{m}$ as shown in Fig. 8, the comparison of the lower curves in Fig. $7 a$ and of the loop voltage in Fig. 7b represents a sensitive test of the current distribution and penetration, and of the plasma resistivity and hence of the transport model used.

It is interesting to note how well the computed loop voltage in Fig. $7 b$ agrees with the measured value in the time period $0.30<t<0.44$ in 
particular. Even with the plasma current increasing from $300 \mathrm{kA}$ to $400 \mathrm{kA}$ in this period, the loop voltage differs by only a few percent. The difference between the theoretica: and experimental loop voltage curves in the iritial time period $0.25<t<0.28$ is not significant, being due only to a rather bad choice for the initia! equilibrium current distribution. As the plasma profiles evolve in time acsording to the transport equations in TSC, the ; dependence of the curves on the initial conditions diminishes, and the theoretical and experimental curves begin to match after about $30 \mathrm{msec}$, which is comparable to tire energy confinement time.

of more physical significance is the disagreement between the theoretical and experimental loop voltage curves in the time period $0.44<t<0.58$. This is the time period over which the two Neutral Bean Injectors oriented parallel to the magnetic field were activated. Separate analysis of this shot by the TrANSP code shows that these high energy injected particles carry on the order of $10 \%$ of the total plasma current. Since our plasma resistivity model makes no attempt to simulate bighiy nonthermal current carriers, we expect the theoretical and experimental curves to differ in this time span.

\section{B. Axisymetric Instability}

To model a disruptive thermal quench, we abruptly increase the transport multiplier $f_{m}$ at time $t=0.566 \mathrm{sec}$ from $0.6 \mathrm{tc}$ a value in the range 0.8 to 2.0. Tho plasma beta reduces accordingly and the plasma comes into a new equilibrium with the same total current at a decreased value of major radius with its magnetic axis in the range $R=1.34$ to $R=1.44$ meters. With the vertical feedback system turned of $f$ and the passive plate resistivity reduced to zero, we give the plasma a small rigid vertical perturbation and observe its behavior. If the passive plates are not sufficient to provide ideal time 
scale statillty, the Z-position of the plasma magnetic axis will exhibit exponential growth, otierwise it will return to th" midplate, indicating stability.

We sumnal ize the results of this study in Fig. 9 where we plot the square of the unstabl: growth rate for the vertical instability as a runction of the new radial pesition of ths magnetic axis after the thermal quench. The stability boundary for axisymmetrio displasements is seen to ve approximately $R=1.39$ meters, which corresponds to a decrease in 9 from $4 \%$ to $3 \%$. If the plasma displaces to a magnetic axis position less than this, the plasma will be lost.

Also shown on Fig. 9 is the computed growth rate of the resistive time scale axisymetric mode using the true value of the passive plate resistivity. This mocle only exists in the region of magnetic axis locations that is stable for zero plate resistivity. This curve was obtained in the same manner as described above, except that the passive plate resistivity was not changed from its original value when the + ort multiplier was increased.

We see that the finite resistivity mode has a pole at the ideal stability boundary $I \equiv 1.39$ meters. This is consistent with the simple scaling [3]

$$
r=r_{R} \frac{r_{O}^{2}}{r_{S}^{2}-r_{O}^{2}},
$$

where $Y_{R} i:$ the inverse $L / R$ decay time of the plates. $Y_{0}$ is the ideal MHD growth rate if no walls were present, and $Y_{S}$ measures the stabilizing effect of the plates if they were perfectly conducting.

The resistive time scale growti rate increases rapidly as the plasma major radius decreases from the pre-disruptive value of $k=1.45 \mathrm{~m}$ to the 
ideal stability boundary at $R=1.39 \mathrm{~m}$. At some value of major radius in the range $1.39<\pi<1.45$, the active feedback system clearly becomes inadequate and the axisymetric stability will be lost, even though the system is ideal MHD stable.

A typical unstable sequence is shown in Fig. i0 where we see in (a) a high beta plasma equilibrium which in (b) displaces to a smaller major radius due to a disruptive thermal quench and in (o) displanes exponentially off the midplane due to the axisymmetric instability.

In Fig. 11 we plot a comparison of the time histories of the poloidal field during the last $6 \mathrm{~ms}$ as measured by seven Mirnov coils and as computed for PBX shot " 95732 . This shot is virtually identical to the previously discussed shot, \#95737, but has Mirnov coil data available for this time period. The coil locations are indicated in the figure and described further in Ref. [8]. We note here that coils $8,13,15$ are in the same poloidal location but are rotated toroidally $120^{\circ}$ from each other, and similarly for coils 2, 16. The computed fields in each of these coil sets will always be identical since the computation assumes axisymmetry. The fact that the measured values are nearly identical for each set shows that the discharge termination is nearly a:isymmetric for this shot. He also note that the orientation of coils 2,16 is opposite to that of the others.

To model the disruptive event, we increased the thermal transport coefficients at $t=592 \mathrm{~ms}$ to cause the plasma beta to suddenly decrease from $4 \%$ to $2 \%$ in $0.5 \mathrm{~ms}$. The plasma shifts inward in major radius to a magnetic axis position of approximately $140 \mathrm{~cm}$. A small initial vertical displacement (0.5 $\mathrm{cm}$ in the simulation) causes the plasma to displace upward, as shown in Fig. 10, and by $t=594$ ms it is decaying in the upper left corner of the vacuum vessel. 
From comparing the experimental and theoretical traces in $F$ ig. 11, we can conclude that there is good qualitative agreement between the simulation and the data. The experimental traces clearly exhibit a radial contraction phase in which the plasma moves inward. This shows itself as an increase in all the loops during the first $0.5 \mathrm{msec}$ except for the outboard ones, 2 and 16 which decrease. In the next phase, lasting approximately $2 \mathrm{msec}$, the loops 8,13 , 15 decrease while loop 7 increases as the plasma displaces vertically upward. Firally, all the loops decrease as the plasma current quenches. Fram the stability diagram on Fig. 9 and from the slopes and amplitudes of the Mirnov measurements on Fig. 11, we see that the plasma never became ideal MHD unstable, but was lost due to an axisymmetric instability whose growth rate scales with the wall resistivity. An ideal time scale instability would appear as instantaneous, or as a vertical line, on this time scale.

\section{SUMMARY AND CONCLUSIONS}

We have demonstrated that the vertical instabilicy is an important fautor present in the high beta operation of PBX. Although the plasma is stable during normal high beta operation, small departures from this normal operation such as the major radius shift associated with the thermal quench phase of the plasma disruption will cause loss of axisymmetric stability. It is a+so possible, as speculated in Ref. [8], that slight inward radial exoursions due to large sawtooth oscillations at high beta, high Indentation operation will be sufficient to cause the plasma to lose axisymmetric stability.

It is significant in itself that $P B X$ is able to operate in a stable manner so close to th.3 instability boundary. This demonstraticn should have impact on the design of other noncircular tokamaks. We can conclude that precision design of tokamaks that rely on conducting walls for ideal time 
scale stability is now warranted, but that knowledge only of the ideal MFD axisymetric stability boundary is not sufficient to guarantee stability. Oile must evaluate the growth rates of modes that depend on finite wall resistance near the ideal MHD stability boundaries.

The comparison with cortrolled experimental calibration runs described in Sec. II gives credibility to the numerical simulation results presented in Sec. III. In addition, we conclude that the simulation program TSC should prove of value in the inicerpretation of data from other existing experiments as well as in the planning and the modification of new experimerts.

\section{ACKNOWLEDGMENTS}

We are indebted to the remainder of the PBX group for making their data freely available and for cooperation and encouragement in its analysis. Drs. P. Couture and R. Fonck, deserve special mention. We also ac nowledge useful discussions with Drs. A. H. Boozer, M. Redi, and W. M. Tang.

This work has supported by inited States Department of Energy Contract No. DE-ACO2-76-CHO-3073. 


\section{APPENDIX}

\section{Transport Model}

In the simulations presented in this paper, we use a two-regime anomalous transport model with neoclassical resistivity. The model is a generalization of Tang's [9] profile-consistent microinstability model to general axisymetrio geonetry.

We take the electron thermal conductivity to be of the form [10]

$$
x_{e}=f_{m}\left[\left(x_{O H}^{\circ}\right)^{2}+\left(x_{A U X}^{\circ}\right)^{2}\right]^{1 / 2} F(0)
$$

Where the form factor $F(\$)$ is

$$
F(\varphi)=\frac{n_{e^{(0)}}}{n_{e}(\Phi)} \frac{P(\varphi)}{P\left(\phi_{0}\right)} 8_{\pi}^{2} \frac{\phi_{0} R}{\langle d V / d \Phi)|\nabla \Phi|^{2}} \exp \left(\frac{(2 / 3) a_{q} \varphi_{0}}{\varphi_{0}}\right) .
$$

Here $\Phi$ is the toroidal magnetic flux, equal to $\phi_{0}$ at the plasma edge, $P(\Phi)$ is the heating power (Ohmic plus auxiliary) inside the surface $\phi, n_{e}(\theta)$ is the electron density profile, given by Eq. (1), $R$ is the major radius of the magnetic axis, $V(\Phi)$ is the flux surface volume, and $a_{q}$ is taken to be

$$
a_{q}=q_{e}+0.5
$$

where $q_{e}$ is the safety factor at the surface containing $90 \%$ of the toroidal flux between the magnetic axis and the plasma-vacuum interface. From Ref. 9 , we obtain for the two confinement regimes in Eq. (A-1)

$$
x_{\mathrm{OH}}^{0}=\frac{4.0}{n_{e}(0)} \frac{a\left(R B_{T}\right)^{0.3} z_{\text {eff }}^{0.2}}{R^{2.2} q_{e}^{1.6}}
$$




$$
x_{A U X}^{0}=(0.09)\left|\frac{P(\varphi)}{n_{e}(0)}\right|^{0.6} \frac{1}{\left(R B_{T} q_{a}\right)^{0 . B_{a}} 0.2}
$$

where $a$ is the average minor radius and $B_{T}$ is the vacuum toroital field strength on axis. Ail quantities are MKS except the power $P(M W)$, and the central electron density $n_{e}(0)\left(10^{20} m^{3}\right)$.

The multiplier $f_{m}$ is constrained to be unity before the neutral beams are turned on, then varies In the range 0.6 to 1.8 as shown in Fig. 8 . We take the ion thermal conductivity equal to the electron value given by $\mathrm{Eq} .(\mathrm{A}-1)$.

A general geometry generalization of the neoclassical resistivity of Ref. [11] was used, with the calculation of the particle trapping fraction taken from Ref. [12], and the resistivity inside the $q=1$ surface set equal to the value at that surface. 
REFERENCES

[1] BOL, K. et al., "The Princeton Beta Experiment PBX," Princeton Plasma Physics Laboratory Report, PePL-2032 (1983).

[2] OKABAYASHI, M., BEIERSDOREER, P., BOL, K., et al. in Plasma Pnysics and Controlled Nuclear Fusion Research 1984, (Proc. 10th Intl. Conf., London, 1984), Vol. I, IAEA, Vienna, 229.

[3] JARDiN, S. C., LARABEE, D., kucl. Fusion 22, 1095 (1982).

[4] JARDIN, S. C., POMPHREY, N., DELUCIA, J. L., "Dynamic Modeling of Transport and Positional Control of Tokamaks," Princeton Plasma Physics Laboratory Report, PPPL-2258 (1985) (co appear in J. of Comput. Phys.).

[5] Marcus, E., JaRdiN, S., hofFMaNn, F., Phys, Rev. Lett. 55, 2289 (1985).

[6] MIDZUNO, Y., BELL, M., DELUCIA, J. L., JARDIN, S. C., POMPHREY, N., TANG, W. M., "Axisymetric Modeling of TFTR," Bull. Am. Phys. Soc. 30, $1524(1985)$.

[7] MERRILL, B, JARDIN, S. C., "DSTAR: A Comprehensive Tokamak Resistive Disruption Model for Vacuum Vessel Components," submitted to Nucl. Fusion Tech.

[8] ITAMI, K., JAHNS, G., YAMADA, H., MCGUIRE, K., "Classification of Disruptions in PBX," Princeton Plasma Physics Laboratory Report, PPPL$2260(1985)$.

[9] TANG, W. M., "Micrainstability-Based Model for Anomalous Thermal Confinement in Tokamaks", Princeton Plasma Physios Laboratory Report, PPPL-2311(1986).

[10] GOLDSTON, R., Plasma Phys, and Cont. Fusion 26, 1984.

[11] HIRSHMAN, S., HAWRYLUK, R., Nucl. Eusion 17, Si1 (1977).

[12] HIRSHMAN, S., JARDIN, S. C., Phys. Fluids 22. 731 (1979). 
FIGURE CAPTIONS

FIG. 1. Vertical field syster test without plasma. (a) experimental currents, (b), (c) theoretical (code) and experimental flux differences, (d) flux contours.

FIG. 2. Shaping field system test without plasia. (a) experimental currents, (b), (c) theoretical (code) and experimental flux differences (d) flux contours.

FIG. 3. Radial field system test without piasma. (a) experimental currents, (b) theoretical (code) and experimental flux differences (c) flux contours.

FIG. 4. Magnetic flux contours for vertical stability test at (a) time of feedback shutofi $t=0.400$ sec and (b) $t=0.475 \mathrm{sec}$.

EIG. 5. Comparison of simulation (theory) and experimental values for flux difference between loops 1 and 2 . Also shown is curve for calculation repeated with top and bottom plates moved closer by $4 \mathrm{~cm}$.

FIG. 6. Currents in EF and IF (or SF) systems, and plasma ourrent in experiment and simulacion for high beta shot $\$ 95737$.

FIG. 7. Comparison of experimental and computational flux difierences for high beta shot \#95737 measuring (a) rasial position (upper curves) 
and indentation (lower curves) and (b) loop voltage average between flux loops 3 and 4.

FIG, 8. Neutral beam power and transport multiplier applied in simulation of high beta shot.

FIG. 9. Sealed growth rate for ideal time scale axisymetric instability (left) and for resistive time scale growth rate (right) as a function of magnetic axis position at full current, high beta operatiòn. Active feedback system is turned off to generate these curves.

FIG. 10. Plasma fiux surfaces at three times showing unstable sequence. High beta plasma (a) suffers a thermal quench causing it to move inward in major radius to (b) where it is unstable to axisymmetric instability and displaces of the midplane (c) causing discharge termination.

FIG. 11. Comparison of measured and computed magnetic fields at Mirnov coils for disruption phase of PBX shot $\$ 95732$. 

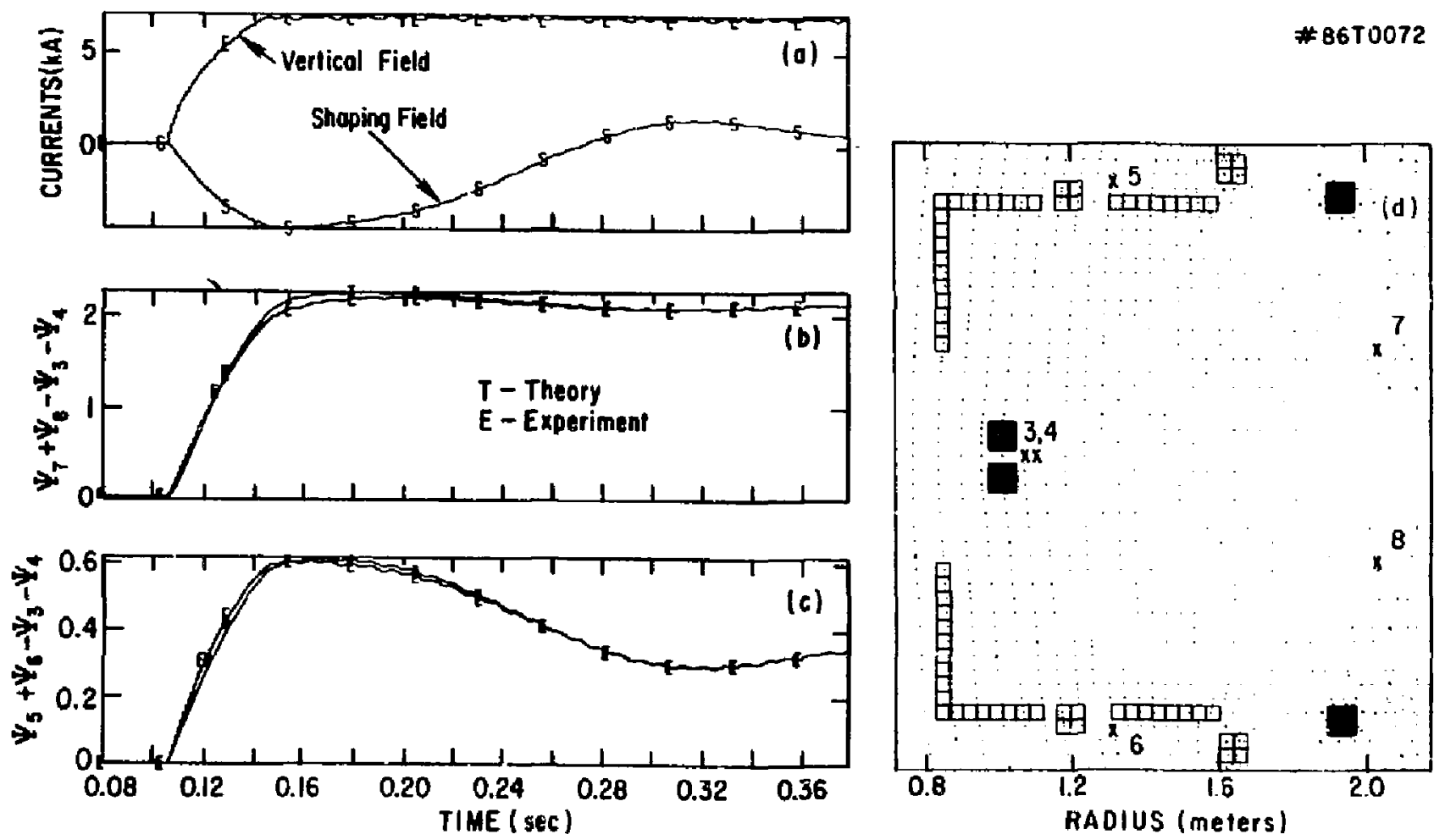

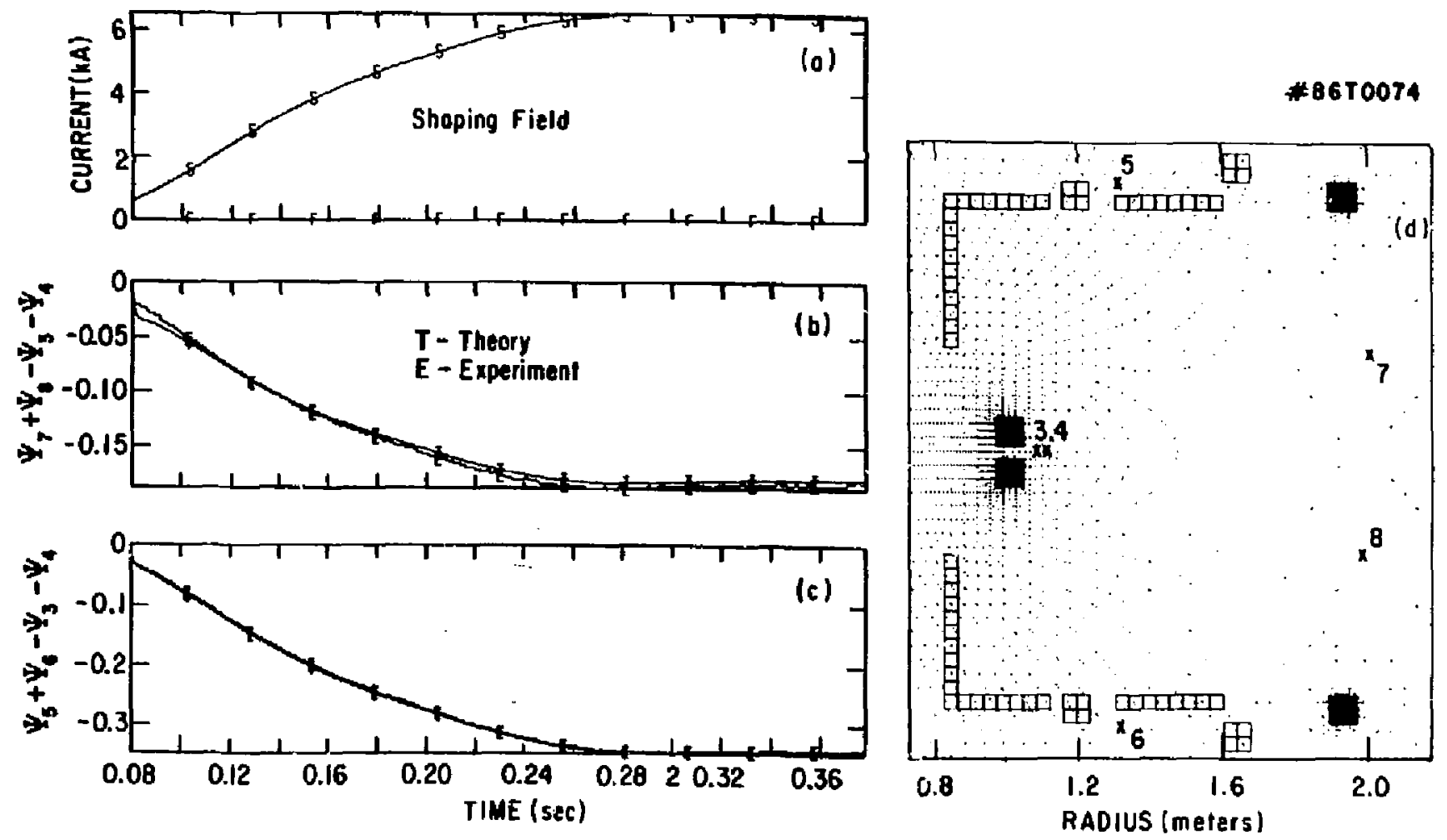


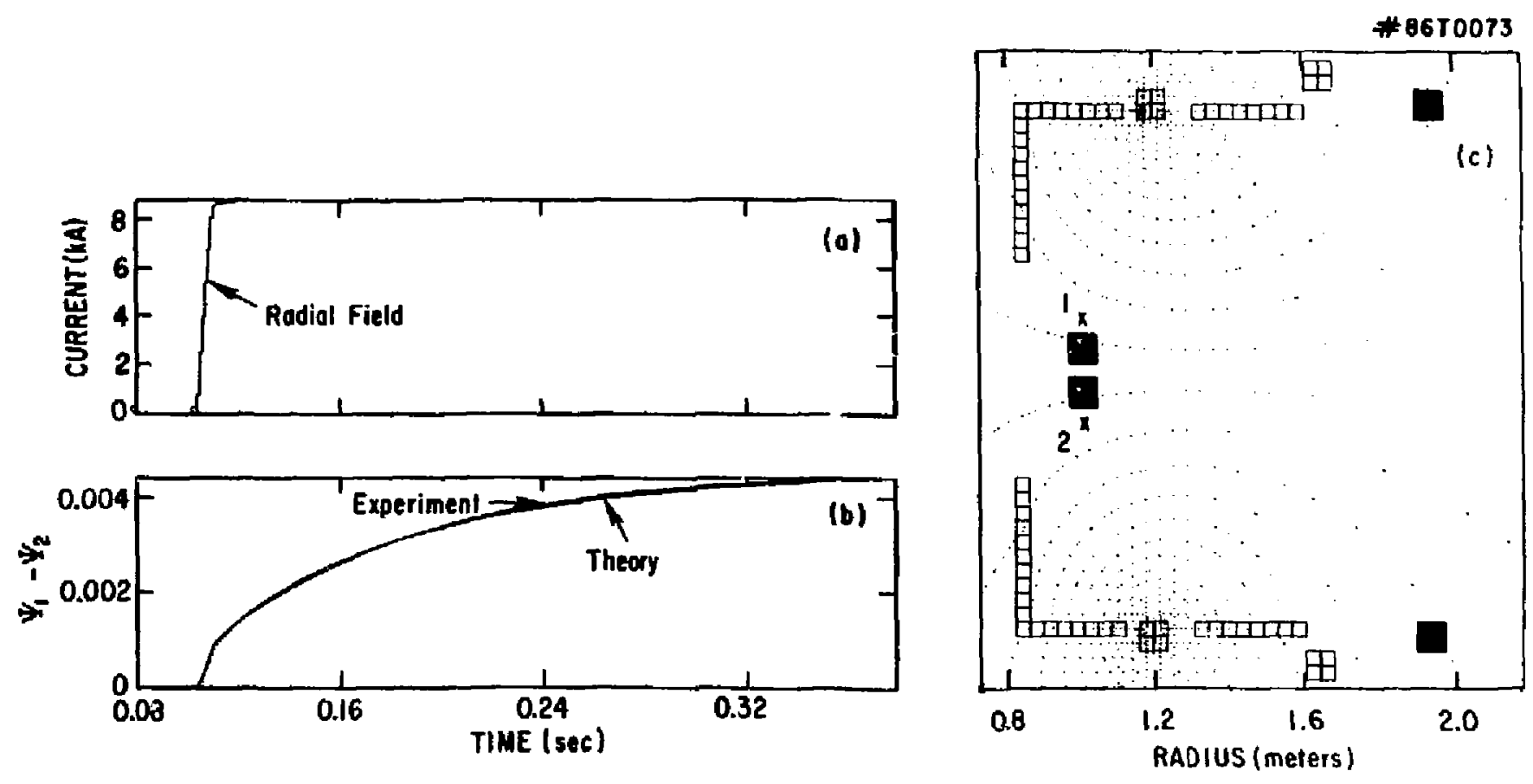

Fig. 3 

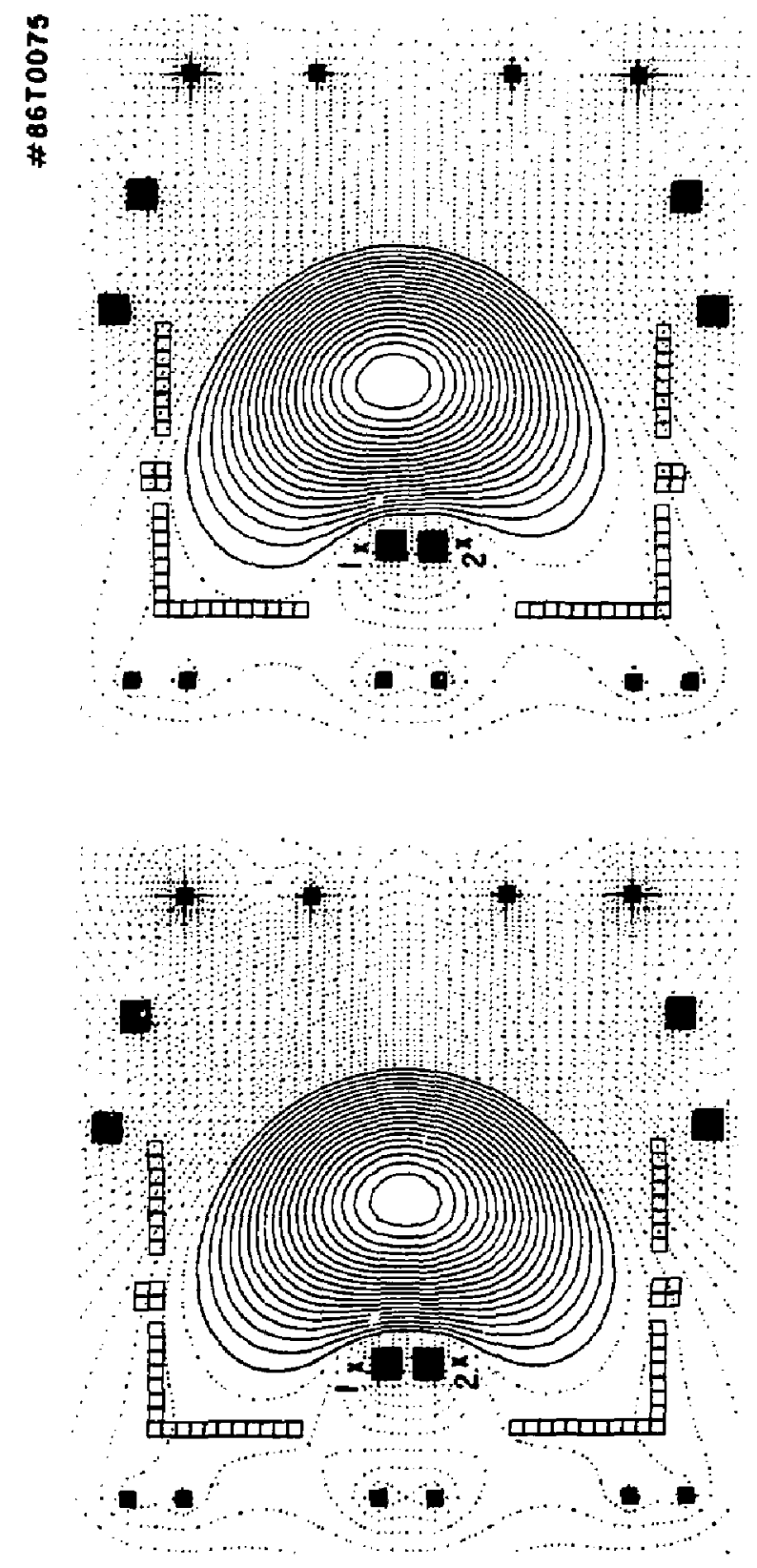


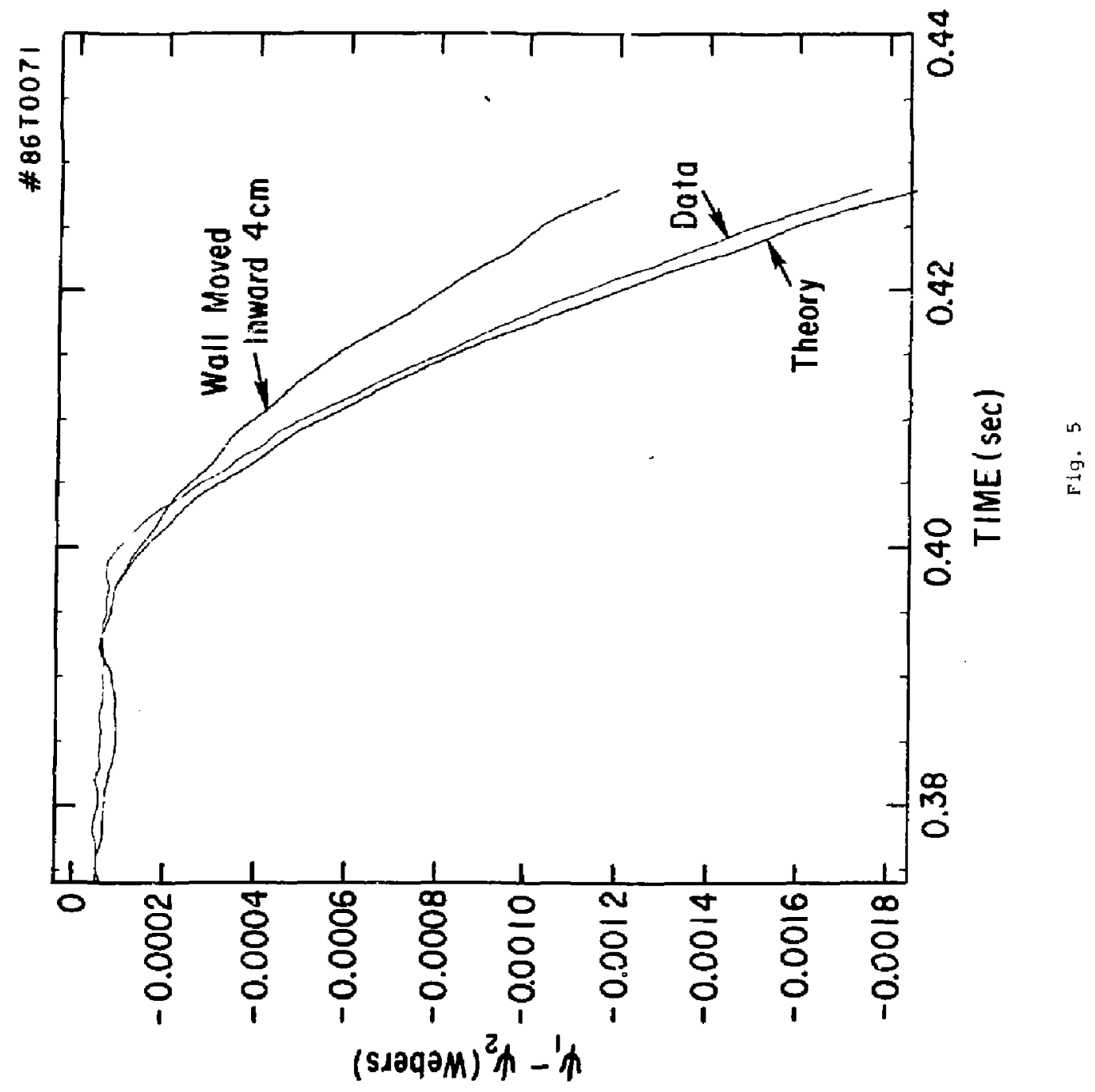




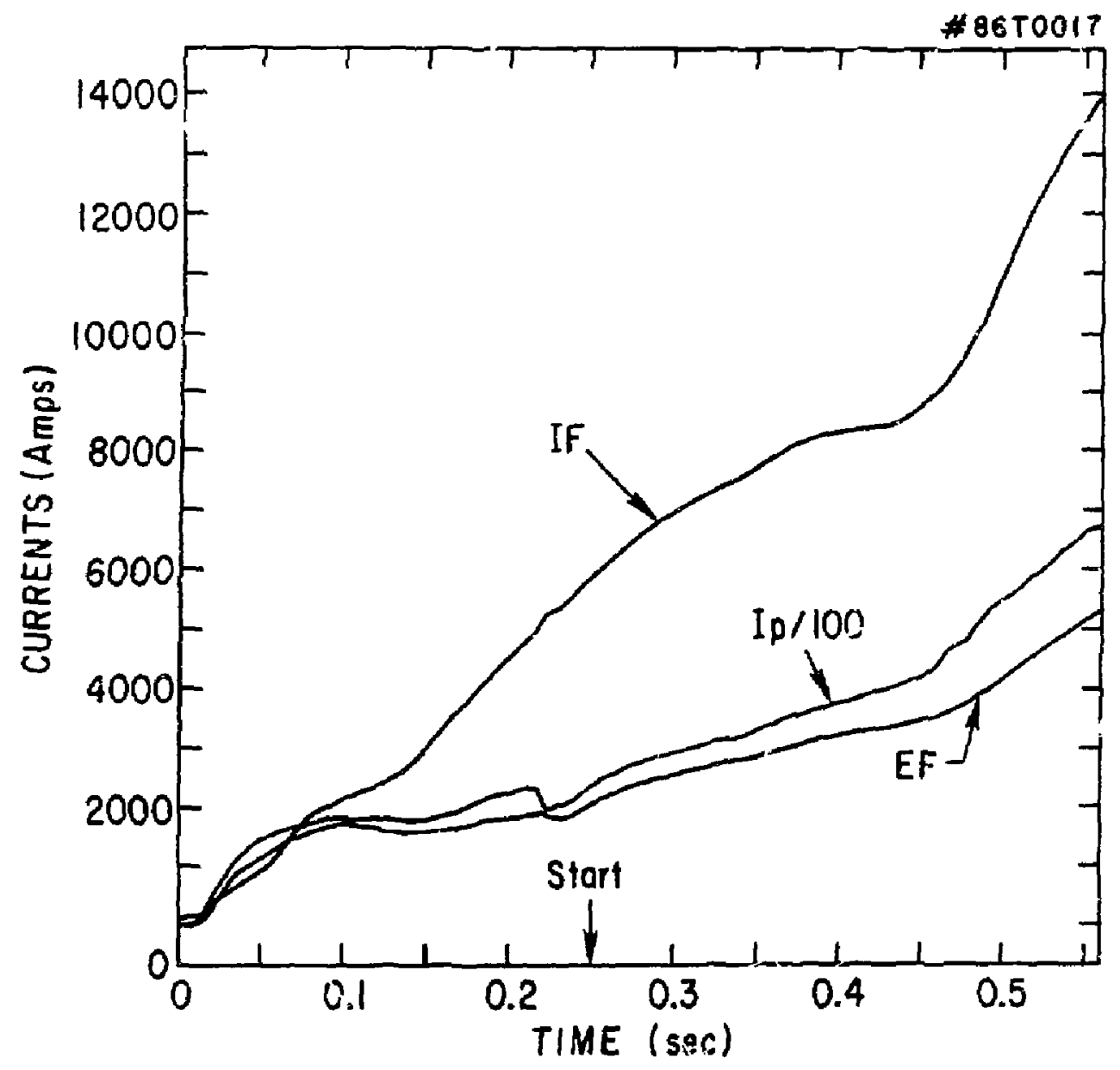

Fìg. 6 

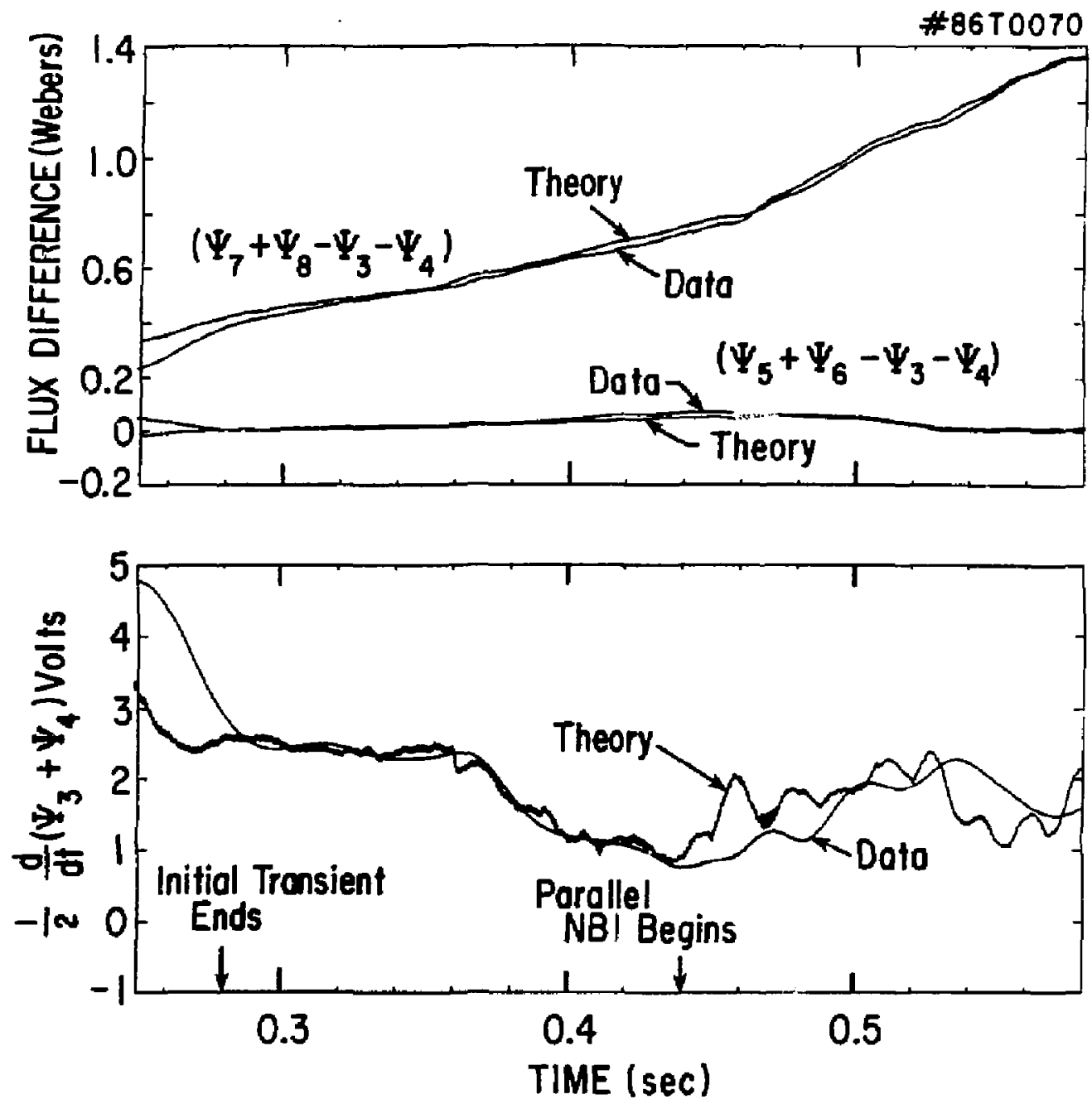

Eig. 7 
\#86T0016

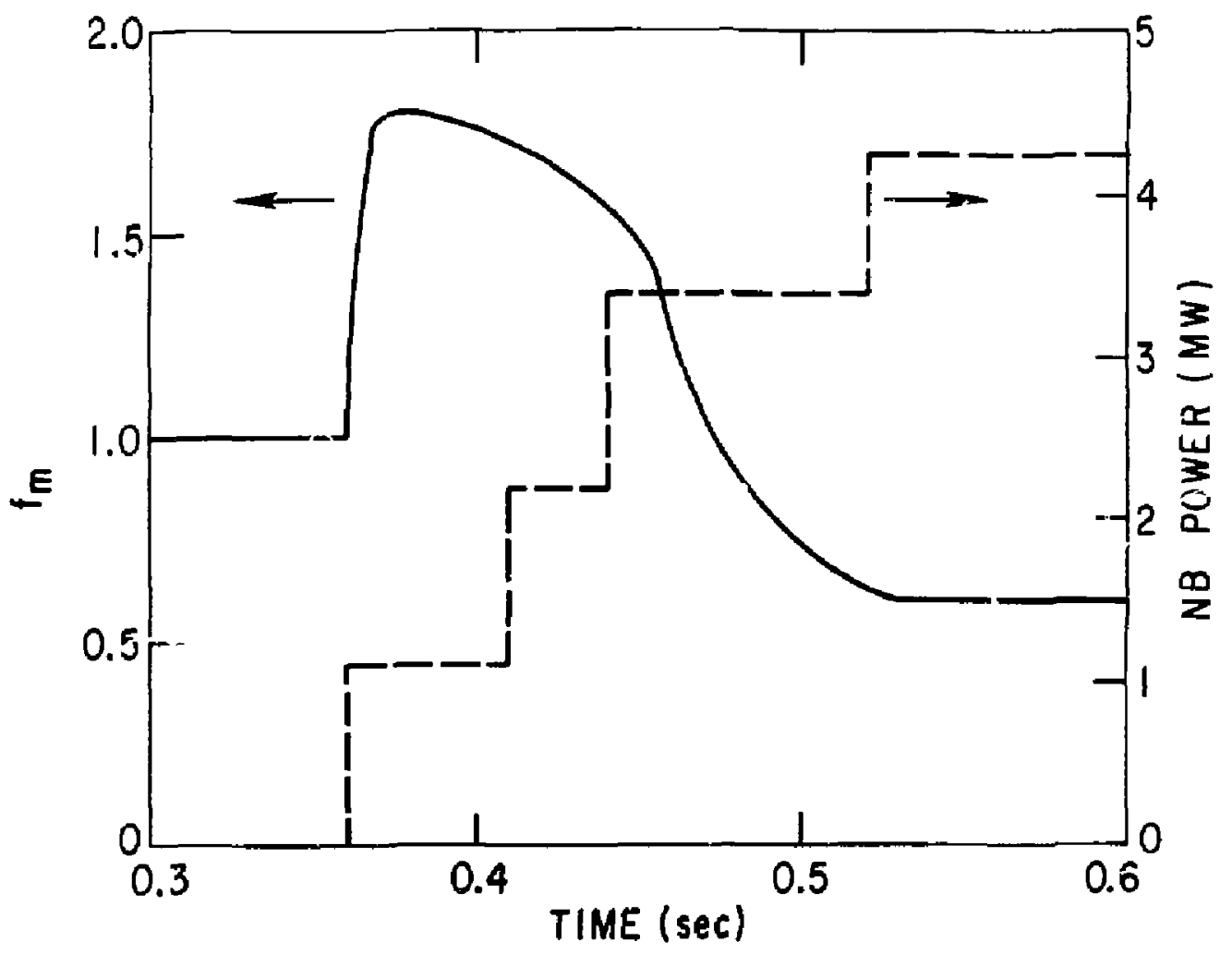

Fig. 8 
\#86T0068

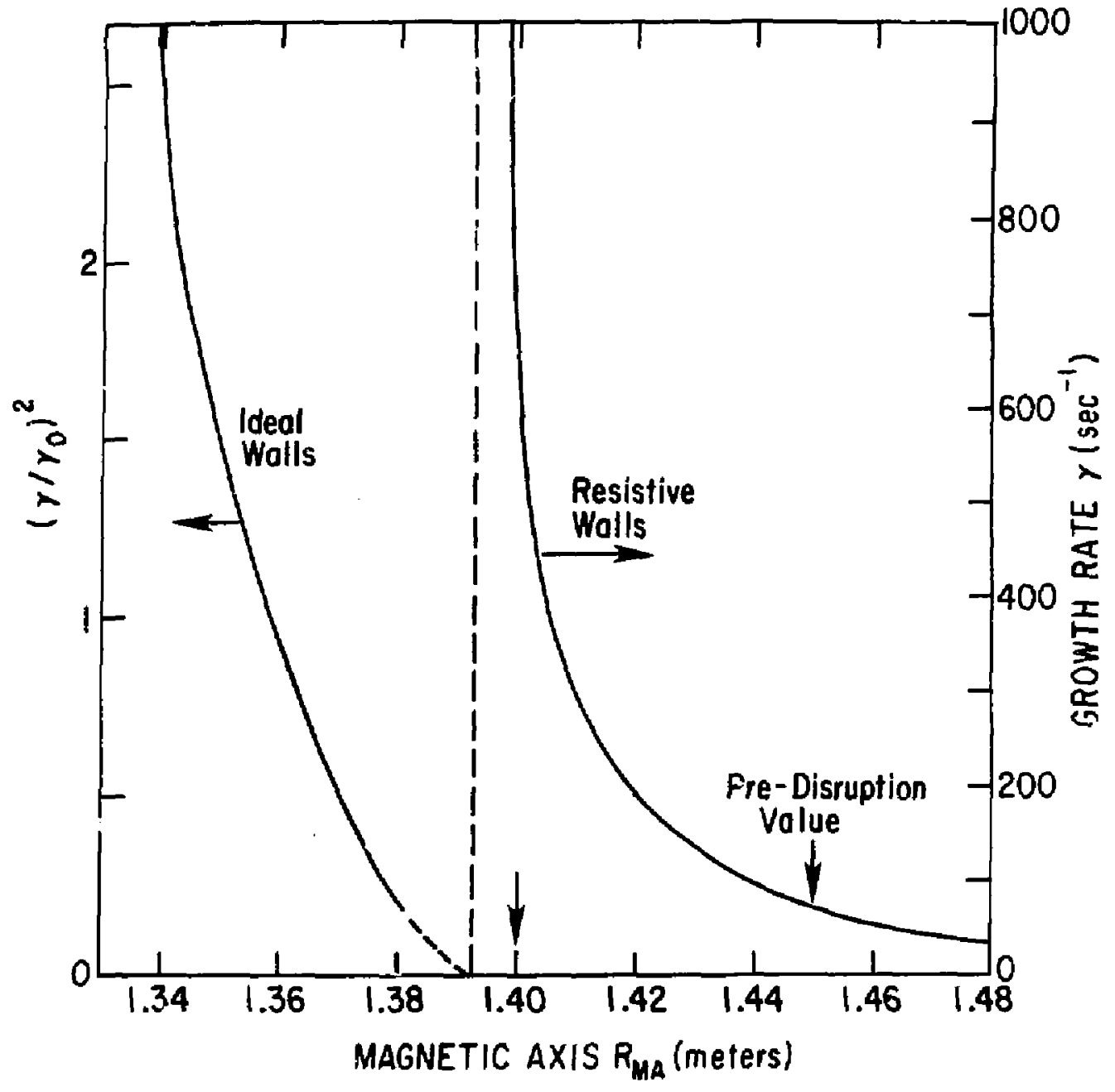

F1g. 9 
\#86T0069

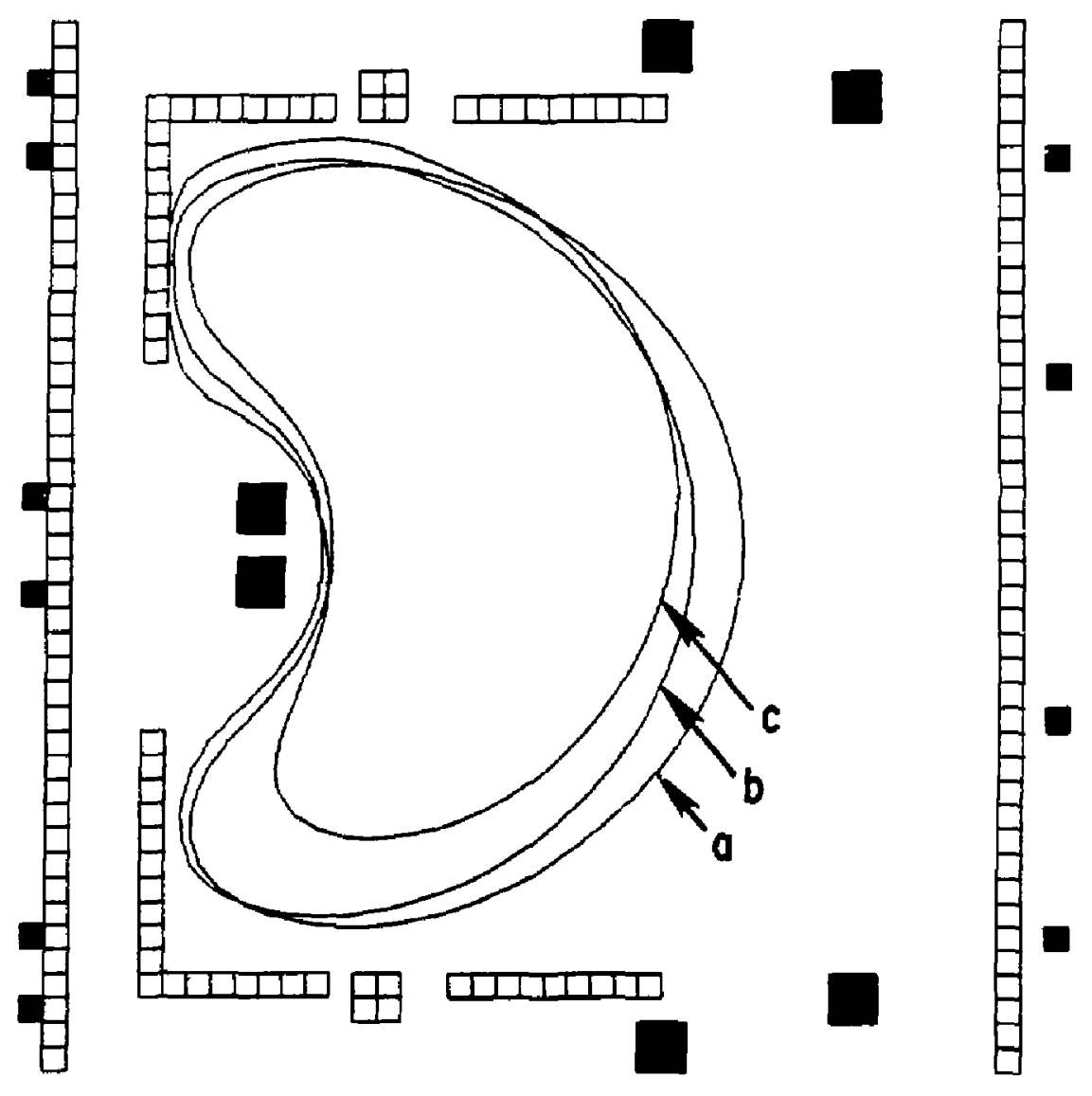

Fig. 10 


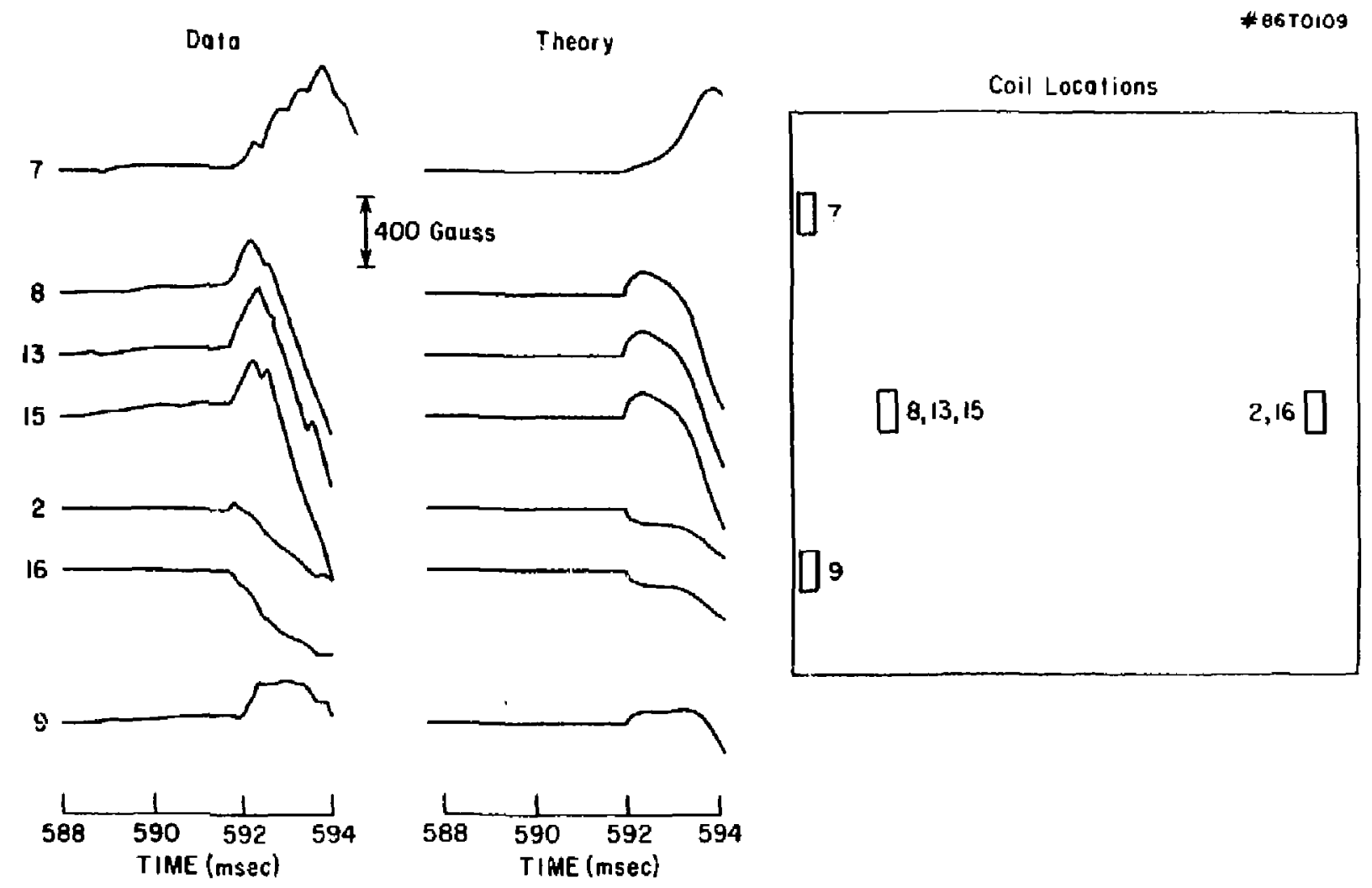

Fig. 11 
Plasmo Ras Lab, Austra Nat'l Univ, Austanlia

Or. Frank J. Psolon I, In iv of wol longong, AUSTRALIA

Prof. 1.R. Jones, Flingers UnIv., AUSTRaLIA

Prot. M.H. Brennan, Unlv Syoney, AUSTRALIA

Pref. F. Cap, Inst Theo Phys, Austria

M. Goossens, Astronomisen Instltudt, BELGIUM

Prof. R. Bouclque, Laborator lum voor Natuurkunde, BELGILH

Dr. D. Palumbo, Dg XII Fuslon Prog, BELGly

Ecole Royale Milltalre, Lab de Phys Plasmes, Belgium

Or. P.H. Sakanake, Univ Estadual, BRRIL

Lib, \& Doc. Dlv., Instituto de Pesquisas Espociala, BRR IL

Dr. C.R. James, Unly of Alberto, CANiDA

Prof. 5. Telchmann, Unlv of Montreal, Canada

Dr. H.M. Skarsgard, Univ of Saskatchemen, Canida

Prof. S.R. Sreenlvasan, Universlty of Calgary, Caneba

Prof. Tudor W. Jahnston, IMRS-Energi B, CANADA

Dr. Hannes Barnard, Unlv BritIsh Columbla, CAMADA

Dr. M.P. Bachynski, wag Jechnolagios, Inc., CANNA

Chalk Rlver, Nucl Lab, CAMoA

Zhenge's L1, SW Inst Physles, CHINA

Library, Tsing Hua Unlversity, CHINA

Librerlan, Institute of Physies. CHINA

Inst Plasmo Phys, Academlo SInlco, Crind:

Dr. Potar Lukac, Komenskeho Unlv, GeChosloyakia

The Librarlan, Culthem Laboratory, ENGLAND

Prof. Schatzman, Observatolra de NIce, FRANCE

J. Ridet, CEN-GPE, FRMNEE

JET Reading Room, IET Jolnt Undertaking, ENGLAND

AM Dudas Ltbrary, aM Dupas LIbrary, FRAMCE

Dr. Tom Mual, Acadeny Blollographle, HOHG KONG

Preprint Library, Cont Res Inst Phys, HUNGARY

Or. R.K. ChnojIanl, Vikram Unlv. INDIA

Or. 8. Dasgupta, Saha Inst, InOIA

Or. P. Kar, Physlcal Research Lab, I Hola

Dr. Phlllip Rosendu, Israel Inst Tech, ISRAEL

Prof. S. Cuparman, Tal Aulv Unlversity, ISRAEL

Prof. G. Rostagnl, Unlv of Padova, ITALY

L! brarlan, Int'l Crr Theo Phys, ITALY

Miss Clella de Pala, Assoe EuRATCM-EnEA, ITALY

Bl bllotece, del GNR ELRATOM, ITALY

Or. H. Yambto, Tosnlda Res d Dev, JAPAN

Direc. Dept. Lg. Tokemak Dev. JAERI. JAPAN

Prot. NobuyukI I noue, University of Tokyo, JAPAN

Research Info Conter, Nagoya Univers Ity, JAPAN

Prof. KYoJI NIsnIkawa, UnIV of HIroshIma, JAPAN

Prof. SIgeru MorI, JAEPI, JAPAN

Prot. S. Tonako, Kyoto University, JAPAH

LIbrery, Kyoto Unlversity, JAPAH

Prot. Ichiro Kawakenl, NIhon UnIv, JAPAN

Prof. Setoshl Itoh, Kyushu Unlversity, JAPAN

Or. D.1. Chol, Adv. Inst Sel \& Teeh, KOAEA

Tech Info DIYISION, KAERI, KOREA
Bl bllothegk, Fom-lnst Voor Flasma, NeTHERLANDS Prof. B.S. LIley, Unlversity of Walkato, NEW ZEALAND Prof. J.A.C. Cabral, Inst Superlar Tacn, PORTUGal Or. Octavian Petrus, ALI CLEA Unlvarcity, ROMANIA Prof. H.A. Helluerg. Unlversity of Natal, SO AFriCA Or. Jothan de Villlers, Plasmo Physles, Nucor, so AFRICA Fusion Div. Llorary, JEN, SPAIN

Prof. Han' WI fhelmson, Chalmer's Unlv Teen, SHEOEN Or. Lennart Stenflo, Unirersity of UMEA, SHEDEN LIbrary, Royal Inst Tach. SWEOEN

Ventre de Rechorchesen. Ecole Poivtech Fed, Sirl ILEgLANo Or. V.T, To!ok, Kharkav Phys Tach I ns, USSR Or. 0.0. Ayutov, STberian Acad ScT, USSR Dr. G.A. EIIseer, Kurchetor Institute, USSR Or. V.A. Glukhlkh, Inst Elactrothyslcal, USSR Ins*ltute Gen. Physicg, USSR

Prot. T.J.M. Boyd, Unly Collage N Wales, WALES Dr. K, Schlndier, Runr Universitot, W, GERMANY ASDEX Reading Rm, IPPMax-lanck-Institut fur

PlasmbohysIK, F,R,G,

Nucleor Res Estob, Julleh Lto, W. GE :AANY Librorlan, Mox-Pionck Institut, W. GERHANY BIbllathek, Inst Plasma forschung, W. GEaMANY Prot, R.K, Janow, Inst Phys, YUGOSLAvIA 